\title{
LETRAMENTO ACADÊMICO INDÍGENA E QUILOMBOLA: UMA POLITICA LINGUÍSTICA AFIRMATIVA VOLTADA À INTERCULTURALIDADE CRÍTICA
}

\section{INDIGENOUS AND QUILOMBOLA ACADEMIC LITERACY: AN AFFIRMATIVE LANGUAGE POLICY TOWARD CRITICAL INTERCULTURALITY}

\section{Letícia Cao Ponso*}

\section{RESUMO}

Este artigo busca refletir sobre um acompanhamento pedagógico intercultural crítico para o acolhimento, a integração e a permanência dos estudantes indígenas e quilombolas no ensino superior brasileiro. Mais especificamente, pretende-se construir o argumento de que as experiências universitárias desses povos tradicionais nos cursos de graduação e pósgraduação só se podem concluir satisfatoriamente se baseadas em políticas institucionais que incluam uma política linguística para falantes de línguas não-hegemônicas, no que se refere ao domínio da textualidade acadêmica em língua portuguesa. Recorre-se aos conceitos de "letramentos de re-existência", "interculturalidade crítica" e "pedagogia decolonial" em busca de propor uma política linguística que contemple os letramentos decorrentes do contato entre línguas e culturas presentes na comunidade acadêmica - especialmente as indígenas - a partir das demandas e agenciamentos de seus próprios falantes.

Palavras-chave: política linguística; letramento; interculturalidade; decolonialidade.

\section{ABSTRACT}

This article aims to reflect on an intercultural pedagogical monitoring for the reception, integration and permanence of indigenous and "quilombolas" students in Brazilian higher education. More specifically, it is intended to construct the argument that the university experiences of indigenous students in undergraduate and postgraduate courses can only be satisfactorily concluded if they are based on institutional policies that include a language policy for speakers of non-hegemonic languages, in the which refers to the domain of academic literacy in Portuguese language. The concepts of "re-existence literacy", "critical interculturality" and "decolonial pedagogy" are used to propose a language policy that contemplates the literacies resulting from the contact between different languages and cultures present in the academic community - especially indigenous ones - from the demands and agency of their own speakers.

Keywords: language policy; literacy; interculturality; decoloniality.

\footnotetext{
* Universidade Federal do Rio Grande (FURG), Rio Grande, RS. e-mail: lecapon@gmail.com
} 


\section{INTRODUÇÃO}

Entre as dificuldades enfrentadas por estudantes indígenas e quilombolas desde que se ampliou o seu ingresso nas universidades brasileiras nas últimas décadas, destaca-se a insuficiência de uma política educacional e linguística voltada ao acompanhamento da acolhida, da integração e da permanência desses alunos nos cursos de graduação a partir de suas próprias demandas e agenciamentos frente às exigências que o ambiente acadêmico impõe. Os esforços para se criarem propostas pedagógicas interculturais têm sido na maior parte das vezes obstaculizados por uma estrutura administrativa monocultural e com baixo grau de flexibilidade tanto para absorver experiências fora dos padrões normativos do sistema nacional de educação superior (BARROSO-HOFFMANN, 2005; FREITAS \& ARDER, 2013), como para lidar com letramentos vernaculares periféricos, não-hegemônicos e socialmente desvalorizados (STREET, 2014; LEA \& STREET, 1998; SOUZA; SITO, 2010 e 2016; ZAVALA, 2010).

Neste artigo, buscamos refletir sobre algumas práticas de letramento acadêmico de alunos indígenas e quilombolas no marco de uma política linguística afirmativa. No âmbito do projeto de pesquisa e ensino "Práticas de letramento acadêmico para uma política linguística de permanência de alunos indígenas e quilombolas na universidade ${ }^{\prime \prime}$, que coordenamos junto ao Instituto de Letras e Artes da Universidade Federal do Rio Grande, analisamos algumas estratégias usadas por esses sujeitos com vistas a melhor integrar-se no ambiente acadêmico, tendo em vista o contexto de assimetria sociocultural com que se deparam nos primeiros semestres da graduação. Por meio de uma pesquisa qualitativa de cunho etnográfico, envolvendo a observação participante das práticas em torno da produção de textos e as perspectivas dos participantes sobre ela (LILLIS, SCOTT, 2007), procuramos compreender em que medida as noções de agência e de coletividade são determinantes na apropriação crítica dessa discursividade e na negociação com as normas e as exigências institucionais (ZAVALA, 2011; SITO, 2016).

$\mathrm{O}$ ingresso dos povos tradicionais no ensino superior brasileiro faz parte de uma luta histórica que originou determinações legais voltadas à garantia do exercício de seus direitos culturais diferenciados. A partir dos anos 1990, seguindo

1. Este projeto existe desde 2018, portanto seus resultados ainda são parciais. Seguindo os princípios básicos de Uwe Flick (2008, p. 95-104) para a ética na pesquisa qualitativa, além de buscar o consentimento informado dos sujeitos da pesquisa, buscamos respeitar e assegurar a privacidade dos sujeitos. Para garantir-lhes o anonimato, os seus nomes foram substituídos por pseudônimos, seguindo a orientação de Fettermann (1989, p. 133), como um meio simples de preservar sua identidade e protegê-los de algum prejuízo. 
um amplo movimento de toda a América Latina, a implementação do ensino superior para as populações indígenas no Brasil ${ }^{2}$ adotou três linhas de ação distintas: a primeira, expressa pela criação de cursos universitários de licenciatura intercultural exclusivamente destinados aos indígenas a fim de suprir a exigência do MEC de uma formação superior para professores que atuariam em escolas bilíngues; a segunda, dirigida à inserção de indivíduos indígenas nos cursos regulares oferecidos pelo sistema universitário, público e privado; e, a terceira, constituída pelas propostas de criação de universidades indígenas (BARROSO-HOFFMANN, 2005).

Por outro lado, políticas educacionais inclusivas para o segmento negro da população recrudesceram quando sancionada a Lei 10.639/2003, que tornou obrigatório o ensino da história e cultura afro-brasileira e africana nas redes pública e particular da educação básica, alterando a Lei de Diretrizes e Bases da Educação Nacional (LDB - 9.9394/1996). O tensionamento que as discussões sobre as relações étnico-raciais produziram entre professores, alunos, pesquisadores e gestores também acendeu o debate sobre as cotas étnico-raciais na educação. Tal debate culminou com a criação da Lei de Cotas 12.711/2012, que determina a reserva de $50 \%$ das vagas das Universidades e Institutos Federais para estudantes que realizaram o ensino médio em escolas públicas, autodeclarados pretos, pardos e indígenas, em proporção no mínimo igual à de pretos, pardos e indígenas na população da unidade da Federação onde está instalada a instituição. Além dessa lei, a Portaria MEC no 389/2013 criou o Programa de Bolsa Permanência, destinado a viabilizar a permanência, no curso de graduação, de estudantes indígenas e quilombolas.

Não obstante, as decisões em relação às políticas linguísticas para estudantes indígenas e quilombolas no sistema educativo superior são geridas em uma arena de interesses que muitas vezes excluem esses discentes das relações sócio-políticolinguísticas da língua hegemônica, bem como reproduzem sua subalternidade e marginalidade. Tal política dá continuidade à colonização linguística que significou

2. O debate à época foi fomentado por uma série de protocolos internacionais ligados à ONU e à OEA. Entre eles, a Convenção 169 da OIT, de 1989, que traz o tema da educação indígena em suas partes IV e VI, e, em seu art. 28, estabelece o direito dos indígenas ao ensino em suas línguas maternas; o projeto de Declaração dos Direitos dos Povos Indígenas na ONU e o projeto de Declaração Americana dos Direitos dos Povos Indígenas, em 1997, com cláusulas específicas apoiando o direito dos indígenas à educação em todos os níveis ensino; e o "Encuentro Regional sobre la Educación Superior de los Pueblos Indígenas de América Latina", na Guatemala em 2002, sob os auspícios do Instituto Nacional para la Educación Superior em América Latina y el Caribe - IESALC, da UNESCO, instituto que produziu um diagnóstico geral de todos os países (2002) e do Brasil, o primeiro levantamento "Educação Superior para Indígenas no Brasil. Mapeamento Provisório" (2003) 
o linguicídio de centenas de línguas ameríndias e africanas e até hoje pressupõe a invisibilidade cultural e a assimilação dos sujeitos colonizados e suas línguas. Por outro lado, esses estudantes têm apresentado um comportamento de resistência (ou re-existência, como propõe SOUZA, 2011), ativismo e protagonismo face a seus direitos linguísticos e a um letramento baseado na agentividade (ZAVALA, 2011).

O artigo está dividido da seguinte forma: em uma primeira seção, recorremos a uma revisão de postulados da área dos Novos Estudos de Letramento (KLEIMAN, 1995; LEA; STREET, 1998; SCOTT, 1999; LILLIS \& SCOTT, 2007; ZAVALA, 2010 e 2011) a fim de 1) refletir sobre os recursos com que uma comunidade de falantes de línguas minorizadas se une para sobreviver/negociar/resistir às relações de poder que subjazem à cultura da língua hegemônica predominante no ambiente acadêmico; 2) compreender o problema à luz de relações educativas antirracistas e decoloniais tal como vêm sendo propostas em outras universidades da América Latina $^{3}$. Entende-se que as relações de colonialidade do ser, do saber e do poder a partir da modernidade colonizadora deixaram marcas ao fim das administrações coloniais e que a submissão dos povos não-europeus à exploração e dominação europeia/euro-americana permaneceu como um grande problema da chamada hoje "colonialidade global" (MIGNOLO, 2008 e 2015; MALDONADO-TORRES, 2008; WALSH, 2007 e 2009).

Na segunda seção, partindo da visão de uma política linguística voltada à interculturalidade crítica, ou seja, pressupondo que as línguas e seu valor social não são neutros, e sim associados a uma agenda política, ideológica, social e econômica (SHOHAMY, 2006), apresentamos alguns exemplos de práticas e eventos de letramento de um grupo de estudantes indígenas e quilombolas da Universidade Federal de Rio Grande. Tais exemplos apontam alguns desafios para uma agenda que contemple os fenômenos decorrentes do contato entre diversas línguas presentes na comunidade acadêmica - especialmente as línguas indígenas - a partir das demandas e das deliberações de seus próprios falantes.

Concluímos que, apesar do conjunto de programas e marcos legais que propiciaram, nos últimos anos, uma política de ações afirmativas para o ingresso de indígenas e quilombolas nas instituições de ensino superior no Brasil, nem sempre se lhes garante uma política correspondente de inclusão linguística. Assim sendo,

3. Conferir os trabalhos de intelectuais como o filósofo argentino Enrique Dussel, o teórico cultural argentino Walter Mignolo, o sociólogo português Boaventura de Sousa Santos, o sociólogo peruano Aníbal Quijano, a pedagoga brasileira Vera Candau, a pedagoga norte-americana radicada no Equador Catherine Walsh, dentre outros, que vêm estudando as concepções decoloniais e as suas potencialidades epistemológicas e políticas no contexto global. 
eles próprios muitas vezes desenvolvem propostas de letramento que valorizem suas línguas, suas práticas culturais e seus lugares de pertencimento étnico.

\section{LETRAMENTOS ACADÊMICOS INDÍGENAS E QUILOMBOLAS E INTERCULTU- RALIDADE CRÍTICA}

As demandas das organizações indígenas por ensino superior ganharam maior visibilidade quando associadas às reivindicações de acesso dos estudantes afrodescendentes, portadores de necessidades especiais e provenientes das redes públicas aos cursos de universidades estaduais e federais. Travado a princípio sobretudo em torno de cotas sociais e raciais para grupos historicamente marginalizados da população brasileira, o debate rapidamente se espalhou, sendo que, no caso dos indígenas, segundo Barroso-Hoffmann (2005), com uma repercussão bem menor e cercado de menos polêmicas, não por um sentimento mais propício a estes últimos por parte das elites brasileiras, mas pelo fato de que, numericamente, a participação indígena em sistemas de cotas regidos pelo princípio da proporcionalidade é bem menos ameaçadora do que a dos afrodescendentes e a dos alunos das escolas públicas (BARROSO-HOFFMANN, 2005, p. 6).

Para além de os estudantes indígenas compartilharem com os outros grupos de alunos cotistas, como os afrodescendentes, a questão da origem social e dos efeitos da discriminação racial, acrescenta-se ao debate sobre as ações afirmativas como compensação pelos danos históricos da colonização algumas dificuldades específicas de integração desses sujeitos na universidade. Um desses problemas toca em uma dicotomia firmemente estabelecida no senso comum: aquela que coloca, de um lado, os "saberes tradicionais" (pensados como algo a ser resgatado, recuperado, afirmado, valorizado, etc.) e, de outro, a "ciência ocidental", construídos como um par de opostos em descontinuidade e com difíceis possibilidades de diálogo (BARROSO-HOFFMANN, 2005; FREITAS, 2015). Essa oposição origina, e muitas vezes justifica, a exclusão dos conhecimentos e métodos de transmissão específicos das populações indígenas e quilombolas dentro da universidade ${ }^{4}$.

Há, por exemplo, uma quebra na continuidade da educação intercultural bilíngue de muitas escolas indígenas de Ensinos Fundamental e Médio, que não encontra viabilização curricular nos cursos de graduação das universidades. Salvo cursos específicos de Licenciatura Intercultural Indígena ${ }^{5}$, o ensino superior

4. Uma exceção digna de reconhecimento é o projeto Encontro de Saberes idealizado pelo antropólogo José Jorge de Carvalho.

5. Cf. http://portal.mec.gov.br/prolind 
brasileiro não está preparado para receber alunos indígenas. Sobre essa questão, Barroso-Hoffmann assinala:

\begin{abstract}
Mesmo as propostas existentes de criação de universidade indígenas têm acrescentado pouco no que diz respeito à formulação de conteúdos curriculares específicos, restringindo-se, até o momento, à afirmação de princípios genéricos em favor da inclusão dos saberes indígenas na universidade. Em muitos casos, atribui-se a estes não tanto conteúdos específicos, mas um conjunto de qualidades plasmadas sobre a oposição "saberes indígenas" $\mathrm{x}$ "saberes ocidentais" na qual os primeiros são vistos como detentores de atributos como "espiritualidade", "sensibilidade" e "respeito à natureza", e, os segundos, como "cartesianos", "materialistas", "fragmentários", havendo poucas propostas no sentido de concretizar diálogos entre estes saberes e de identificar em que campos eles seriam mais frutíferos, ou mapeando onde e como eles já se dão. (BARROSO-HOFFMANN, 2005, p. 4).
\end{abstract}

Outra questão diz respeito à ausência de uma política linguística clara, não apenas no que se refere ao domínio dos gêneros textuais acadêmicos em língua portuguesa, mas também quanto a novas formas de pensamento a serem decifradas no ensino superior. Acerca das dificuldades educacionais nomeadas pelos próprios estudantes (alguns deles têm uma língua indígena como materna e fala português apenas na escola; outros provêm de comunidades quilombolas isoladas, nas quais não há sequer luz elétrica), o fator mais recorrente é a dificuldade com a língua escrita, pois o entendimento das aulas e dos textos advêm da compreensão do idioma no qual os textos estão escritos e no qual as aulas são ministradas (Cf. o relevante trabalho de tese de NASCIMENTO, 2012). A linguista Theresa Lillis (1999, p. 127) chama de "prática institucional velada" essa demanda dos professores pelo uso de determinados gêneros textuais como se já fossem de domínio dos estudantes. A sociolinguista Virgínia Zavala, que trabalha com educação intercultural bilingue de estudantes quéchua no Peru afirma que o letramento acadêmico "é só uma das formas de se usar a linguagem como parte de uma prática social que ganhou legitimidade por razões ideológicas que se enquadram em relações de poder" (ZAVALA, 2010, p.74). O letramento acadêmico, para esta autora, não é um meio neutro e transparente que, ao mesmo tempo, se utilizaria para aprender uma mensagem epistemologicamente transparente.

A universidade, portanto, não é explícita sobre suas expectativas e suas convenções. Além disso, assume como desviantes, não-legítimas ou equivocadas formas alternativas de leitura, de escrita e mesmo cosmovisões. Desse modo, as atividades acadêmicas, que já causam embaraços e bloqueios na maior parte dos alunos, indígenas ou não, apresentam também a carga de se contrapor às práticas e modos de agir próprios da cultura na qual os estudantes foram socializados. Se estudantes oriundos do meio urbano pouco compreendem dessas convenções 
em torno da escrita acadêmica, o quadro se agrava quando se trata de estudantes indígenas ou quilombolas, provenientes de culturas em que predomina a oralidade.

O professor e antropólogo cultural Brian Street (2014, p. 44) distingue dois tipos de letramentos sociais. O primeiro segue um modelo autônomo, prevalente nos círculos acadêmicos, que enfatiza a identificação e a superação de problemas técnicos da aquisição e reflete uma prática culturalmente específica, associada a "progresso", "civilização", mobilidade social e "decolagem" econômica. O segundo é um modelo ideológico, que questiona as generalizações acerca do letramento como fim "em si mesmo" e concentra-se no processo de socialização na construção do significado da leitura e da escrita, reconhecendo sua natureza ideológica e culturalmente incrustada. Para o autor, o letramento ideológico "trata com ceticismo as declarações de pedagogos liberais ocidentais sobre a "abertura", a "racionalidade" e a consciência crítica daquilo que ensinam e investiga o papel de tal ensino no controle social e na hegemonia de uma classe dominante" (STREET, 2014, p. 44). A fala do estudante Tapirapé, da Licenciatura Intercultural Indígena da Universidade Federal de Goiás, ilustra a construção do significado do letramento ideológico tal como define Street:

A importância do estudo da língua portuguesa para nós como alunos é uma conquista tanto nós como alunos e para a comunidade. Aprender escrever, ler, interpretar, e aprender usar a língua portuguesa como a defesa da comunidade. Para que nós saibamos avançar o inimigo e lutar sobre o direito indígena que está ocorrendo sempre no preconceito. Também para aprender e trazer o desenvolvimento a comunidade como o projeto sustentável e outro que a nossa comunidade precisa. Isso que eu particularmente sempre pensei para desenvolver durante o curso de licenciatura na UFG, mesmo que seja complicado. Mas temos que avançar, conquistar a dificuldade que nós passamos. (TAPIRAPÉ apud NASCIMENTO, 2012, p. 313).

Grupos sociais como universitários indígenas e quilombolas apresentam, entre muitas outras características interculturais, a de não terem a mesma exposição anterior a práticas de letramento que os outros estudantes universitários, o que faz com que o aspecto mais relevante de sua aquisição seja o impacto desta nova cultura diferente, muito antes que os aspectos técnicos da leitura e da escrita. A esse respeito, Street afirma que tal processo envolve certa transferência de valores "ocidentais" para sociedades não ocidentais e pode ser chamado, por conveniência, de letramento colonial $^{6}$ (STREET, 2014, p. 51), situações em que membros de uma cultura estrangeira introduziram sua forma particular de letramento em meio a um povo colonizado, como parte de um processo muito mais amplo de dominação.

6. Street (2014) ainda distingue o letramento colonial, aquele que é transmitido de uma sociedade externa para uma sociedade "iletrada" de letramento dominante, aquele que é difundido pelo grupo dominante a outros membros e subculturas dentro de uma sociedade. 
Se a linguagem molda a forma como enxergamos, sentimos, pensamos e vivenciamos o mundo, muitos dos problemas enfrentados pelos estudantes indígenas e quilombolas se encontram no fato de que o mundo pensado por eles do ponto de vista cultural e linguístico por si só é um fator que amplifica os obstáculos encontrados em sua permanência na universidade. Ademais, subjaz à política linguística elitista (nem sempre explícita) das universidades a ideologia do déficit linguístico, segundo a qual as línguas autóctones são "primitivas", cabendo aos indígenas o aprendizado da língua do outro, a língua historicamente hegemônica com todos os seus aparatos ideológicos (escrita, literatura, gramáticas, ciência, leis), sob pena de permanecerem marginalizados.

A atuação de coletivos indígenas, quilombolas, negros e outras minorias nas universidades guarda estreita relação com os movimentos sociais e culturais da comunidade não-acadêmica e suas práticas de letramento. Alguns desses movimentos atualmente também se apropriam da categoria "re-existência", pensada pela professora Ana Lúcia Silva Souza (2011) para descrever identidades sociais da cultura bip-bop de periferia no exercício cotidiano da construção do conhecimento e da subversão das ordens indexicais de colonialidade. Desse modo, entende-se que os sujeitos não apenas resistem às formas de opressão e exclusão, provocadas pelo sistema-mundo colonial capitalista, como criam novas formas de vida, textualizando experiências, reinscrevendo-se por outros jogos de linguagem, do campo da arte e da política, em um movimento de discursividades contra-hegemônicas e anticapitalistas.

O conceito de letramento de re-existência (SOUZA, 2011) tem sua centralidade na educação antirracista, decolonial e interventora, que diz que é preciso re-existir em um contexto social, político e econômico opressor que exige reposicionamentos dos lugares de atuação, de proposição e de ação política nos quais a linguagem tem papel fundamental. Letramentos de re-existência, portanto, envolvem modos de produzir conhecimentos a partir da insurgência e da resistência contra epistemicídios, da necessidade de um olhar contra-hegemônico no fazer científico, da autonomia e do protagonismo na reinvenção da palavra através de práticas educadoras criativas.

Finalmente, não se pode pensar sobre educação superior para povos tradicionais sem pensar na problemática da interculturalidade e, com ela, a emergência de um outro paradigma de construção identitária, que prima pela associação de povos, grupos sociais, unidades nacionais e comunidades políticas a determinados tipos de conbecimento. É desejável se desfazer um conjunto de essencializações e dicotomias que obscurecem a natureza dos problemas e das posições em jogo, entre as quais 
as de "ciência ocidental" vs. "saberes tradicionais", "universidade" vs. "índios" ou "quilombolas". Enfocar a questão sob outros ângulos permitiria discutir não tanto como promover o diálogo entre ambos, mas de que forma regulamentar as relações que já existem, isto é, as apropriações que já são feitas e que requerem uma discussão, no mínimo, sobre como repartir com as comunidades indígenas os benefícios materiais obtidos com o uso de seus recursos e saberes.

Nesse sentido, sintonizamos com teóricos latinoamericanos da decolonialidade (MIGNOLO, 2003, 2008 e 2015; ESCOBAR, 2003; MALDONADO-TORRES, 2008) e da interculturalidade crítica (WALSH, 2007, 2009 e 2013), para quem os efeitos do domínio colonial não se suspenderam com o fim do domínio territorial da metrópole. Os conflitos de ser-saber-poder continuam nas chamadas nações "pós-coloniais" com as mesmas práticas de oposição e resistência que surgiram no momento em que os primeiros colonizadores imperiais puseram seus pés na América Latina. Seja na produção de conhecimento, nas teorias, nas metodologias, na pedagogia, o pensamento decolonial busca a "desobediência epistêmica" e a (auto)compreensão do mundo através de sua interioridade, de seu espaço geográfico para além do projeto eurocêntrico de modernidade, que negou por séculos (e continua negando) o conhecimento autóctone ameríndio (MIGNOLO, 2008). A transformação epistêmica apoia-se, assim, no respeito à alteridade, na mudança política e em um novo exercício da cidadania que atenderá a um Estado plurinacional (WALSH, 2009) a partir do reconhecimento das múltiplas e heterogêneas reações das populações e dos sujeitos subalternizados à colonialidade do poder.

Em um paradigma de pensamento eurocêntrico hegemônico, ainda que se fale a partir de uma localização particular, assume-se que os conhecimentos são universais, neutros e não situados. Desse modo, o locus de enunciação não é marcado unicamente por nossa localização geopolítica dentro do sistema mundial moderno/colonial, mas é também marcado pelas hierarquias étnicas, de classe, gênero, sexuais, etc.

$\mathrm{Na}$ perspectiva do projeto decolonial, as fronteiras não são somente lugares onde as diferenças entre mundos se tangenciam; são antes lugares enunciativos (conexão entre lugar e pensamento) de onde são formulados conhecimentos a partir de perspectivas, cosmovisões ou experiências dos sujeitos subalternos. Os sujeitos coloniais que estão nas fronteiras - físicas e imaginárias - da modernidade não são seres passivos. Eles podem tanto se integrar à configuração do norte global como podem rejeitá-las. É nessas fronteiras, marcadas pela diferença colonial, que atua a colonialidade do poder, bem como é dessas fronteiras que pode emergir o pensamento de fronteira - ou pensamento de borda - como projeto decolonial. 
Para o sociólogo argentino Walter Mignolo em territórios marcados pela experiência colonial existiria hoje uma <ética discursiva〉 neoliberal que argumenta em favor do reconhecimento da diferença e da inclusão do outro, com uma benevolência que sugere que aqueles a serem incluídos não têm muito a dizer sobre a forma como são reconhecidos e incluídos (MIGNOLO, 2008). A "tolerância à diversidade" restituiria a secular história de usurpações imputadas aos grupos hierarquicamente posicionados em condição de inferioridade.

A pesquisadora Caterine Walsh, da Universidade Andina Simon Bolívar, no Equador, enfatiza a necessidade de se repensar "de onde" se produz "conhecimento". Ela questiona se a produção intelectual é produto social ou acadêmico; se é feita, na verdade, pelos povos e movimentos sociais ou pela universidade.

\begin{abstract}
Enquanto que no interculturalismo funcional se busca promover o diálogo e a tolerância sem tocar nas causas da assimetria social e cultural hoje vigentes, no interculturalismo crítico se busca suprimi-las por métodos políticos não-violentos. A assimetria social e a discriminação cultural fazem inviável o diálogo intercultural autêntico. [...] Para fazer real o diálogo, há que se começar por visibilizar as causas do não-diálogo. E isso passa necessariamente por um discurso de crítica social [...] um discurso preocupado por explicitar as condições [de caráter social, econômico, político e educativo] para que esse diálogo se dê (WALSH, 2013, p. 9).
\end{abstract}

Enquanto a interculturalidade funcional assume a diversidade cultural como eixo central dentro da sociedade do Estado nacional, deixando de fora os padrões e dispositivos que mantêm a desigualdade, a interculturalidade crítica parte do problema de poder, seus padrões de segregação e as diferenças construídas justamente em função deles. $O$ interculturalismo funcional responde a parte dos interesses das instituições sociais, como uma universidade, por exemplo; a interculturalidade crítica, por sua vez, é uma construção das pessoas que sofreram uma história de submissão e subalternização: os indígenas e os quilombolas, por exemplo (WALSH, 2013, p. 10) Então, a base política e cultural da pedagogia intercultural crítica é a restituição do lugar de fala e da produção teórica de sujeitos que até então foram vistos como destituídos da condição de fala e da habilidade de produção de conhecimentos e projetos políticos. Sujeitos de múltiplas vozes, potências, sonhos e ações, que lutam contra a marginalidade, a discriminação, a desigualdade e buscam a transformação social.

\title{
2. POLÍTICAS LINGUÍSTICAS AFIRMATIVAS NO ENSINO SUPERIOR: REPRESEN- TATIVIDADE E RESISTÊNCIA
}

As escolas e universidades têm uma lógica de estruturação e funcionamento próprias da cultura ocidental, eurocêntrica, não-indígena, branca; então, algumas das 
dificuldades enfrentadas pelos estudantes indígenas e quilombolas quando ingressam no ensino superior se devem à adaptação a regras, procedimentos, protocolos cujos motivos e cuja lógica lhes são estranhos. Além disso, há o preconceito e o estigma de não ser nem indígena, nem branco, nem aldeado, nem urbano; de ter deixado muitas vezes de falar a língua de seus pais e avós para usar apenas o português, com medo de que seus descendentes também sofressem a mesma violência simbólica de que os mais velhos foram vítimas. A exigência de um povo de não falar a língua originária, pois esta foi perdida por conta dos assassinatos e extermínios que sofreram, é um dos temas mais polêmicos na autoafirmação de uma identidade indígena dentro de uma cultura dinâmica que está em constante transformação (Cf. DOEBBER, 2017).

As cobranças de que os indígenas "se pareçam como tal" revelam uma ignorância da sociedade branca em relação às consequências sobre seu pertencimento étnico e à dificuldade de estar entre dois mundos. Para os indígenas, assim como para os quilombolas, sua identidade étnica e sua maneira de pensar e de agir estão ligadas ao coletivo, à territorialidade, ao respeito pela natureza e pelos animais, à ancestralidade, à reverência aos mais velhos.

Justamente porque não perderam os fundamentos de uma filosofia afrocentrada ou de uma cosmologia indígena, sobressaem na escrita acadêmica desses estudantes três aspectos textuais que a diferenciam: 1) a evocação aos antepassados: em muitos trabalhos de indígenas ou quilombolas, ou ainda pessoas que estão em contato com línguas e conhecimentos tradicionais, como povos de terreiro, há em primeiro lugar um reconhecimento e uma reverência aos SEUS sábios, aos seus mais-velhos, aos avós, benzedeiras, curandeiros, pajés, xamãs, babalorixás, ialorixás. O modo de introduzir (seja um trabalho monográfico, seja sua defesa diante de uma banca) já rompe com muitos aspectos do saber acadêmico colonizado, com o questionamento dos formatos introdutórios legitimados na academia: antes de tudo, eles pedem permissão e proteção aos ancestrais, reverenciam a árvore orixalógica, evocam suas divindades e seus poderes/saberes; 2) o compromisso de assumir uma voz em primeira pessoa, com autonomia, originalidade de pensamento e de escrita, contrapondo-se aos parâmetros de impessoalidade, racionalidade, objetividade dos letramentos acadêmicos (o que caracteriza a colonialidade do poder, conforme MIGNOLO, 2008). As bases do texto geralmente envolvem afetividade, intuição, memórias, um "sentipensar", hibridez de gêneros textuais; 3) as escolhas dos temas de pesquisa em geral são autobiográficas, a partir de uma base fenomenológica, originando-se de experiências práticas, concretas, vivenciadas por anos e anos, as quais rompem com a antinomia sujeito/objeto, em que o pesquisador é neutro, um ponto zero, um simples observador. 
Assim, se por um lado o letramento vernacular dos estudantes indígenas e quilombolas é tensionado pelo letramento dominante da universidade desde o processo seletivo de ingresso até a elaboração do trabalho de final de curso, por outro eles próprios criam condições de letramento e de produção de conhecimento em que expressam e elaboram suas dificuldades de se apoderar da escrita acadêmica, discutindo inclusive em que língua, em que português deve acontecer a produção de conhecimento dentro da academia por estudantes que trazem dentro de si uma matriz epistêmica indígena e africana tão fortemente enraizada:

\begin{abstract}
Se a Mãe Natureza através do calor de um raio, da leveza da poeira ou da miséria humana escreve histórias de resistências, então por que no mundo acadêmico precisamos seguir padrões de escrita que massificam os textos e lhes roubam o prazer de existir? PRECISAMOS SER TODOS, UNIVERSALMENTE, FONTE ARIAL 12 COM ESPAÇAMENTO 1,5? É muito difícil, para quem luta pela visibilidade, esconder-se atrás de um padrão de escrita em que os textos, por vezes, não carregam a nossa identidade, porque em algumas situações não nos é permitido explorar nossos limites; e nossas palavras hermeticamente rebuscadas aplacam nossos sentimentos que, envidraçados, se desidratam e se mumificam. (Sônia, estudante negra, mestranda em Educação Ambiental)
\end{abstract}

No início, nos primeiros semestres, afirmam que a linguagem com que se deparam é refratária e impermeável: "eu fiquei o primeiro semestre inteiro ouvindo os professores sem entender uma só palavra do que diziam; eu olhava para eles como se olhasse uma parede... eu chegava em casa e só chorava", rememora uma estudante quilombola durante a escrita do teu trabalho de conclusão do curso de Pedagogia na FURG. Via de regra, nos primeiros semestres, os alunos apresentam queixas de que não estavam preparados para "aquilo tudo" mas "os professores sempre cobram como se estivéssemos". Segue a este primeiro impacto uma vontade de desistir do curso, tentativas de retorno às suas aldeias ou comunidades, reunião com as lideranças e familiares, conselhos dos mais velhos, crises de ansiedade e de depressão, acompanhamento pedagógico e psicológico na universidade.

\begin{abstract}
No início, ninguém queria fazer trabalho de grupo comigo. Eu fazia todos os trabalhos sozinha. Um dia eu pedi pra umas gurias se eu podia fazer o trabalho no grupo delas, e elas me responderam que não. Eu fiquei muito, muito triste. Todos os dias do primeiro ano eu pensava em desistir. Aí passou o tempo. Um dia, na aula de Direito Indígena e Quilombola, essas mesmas meninas pediram pra entrar no meu grupo. Tu acha que eu me neguei? Eu disse: "Podem fazer". Porque nós, indígenas, não somos assim, de não ajudar o outro, de ser egoísta. (Luana, etnia Guarani, estudante de Direito)
\end{abstract}

Esse choque inicial e a busca por ajuda levam a um sentimento coletivo de que é necessário resistir e, para isso, é necessário unir-se aos iguais. Na Universidade Federal do Rio Grande, por exemplo, há quatro coletivos de estudantes: Coletivo Indígena, Coletivo Quilombola, Coletivo Macanudos de Negros e Negras de 
Rio Grande e Coletivo Camaleão de Defesa da Diversidade Sexual e Identidade de Gênero. A partir da representatividade e do acolhimento que encontram nos coletivos, agentes de ação política para a construção identitária de um grupo, estudantes indígenas e quilombolas começam a apoderar-se de estratégias discursivas para afirmar e protagonizar a negociação entre diferentes práticas de letramentos. É nos movimentos sociais e estudantis que os alunos substituem a lógica do fracasso por não dominarem os discursos legitimados pela academia pela lógica de uma crítica a esses discursos. A língua, então, passa a ser usada com funções sociais e políticas, orientadas para o domínio crítico de práticas de letramento dominante, com o objetivo comum de assegurar a permanência desses estudantes na universidade.

Zavala afirma que

o letramento acadêmico deveria cumprir um papel crítico e não paliativo no ensino superior, o que implica combater os discursos de déficit acerca da falta de lógica e de racionalidade nos aprendizes. Necessitamos de uma mudança em uma visão da conquista/fracasso baseada na habilidade e na instrução a uma que considere o estudo nesse nível como uma aprendizagem de novas formas de pensamento e de expressão para os estudantes (ZAVALA, 2010, p. 91).

Ao analisar em sua tese de doutorado a invisibilidade da permanência nas ações afirmativas da educação superior em uma universidade brasileira e outra colombiana, Sito (2016, p. 173) atribui entre as causas uma preocupação com ações no âmbito da assistência estudantil, como os auxílios para alimentação, bolsa permanência e moradia. Além disso, a discussão da sociedade que mais gera polêmica e é veiculada pela mídia é a questão do ingresso:

Consideramos que a centralidade das políticas na modalidade de ingresso, mais do que na permanência, está relacionada à polêmica criada em torno das cotas. Os posicionamentos acirrados, favoráveis ou contrários às cotas, geraram um debate que buscava apenas provar se as cotas eram ou não o instrumento adequado no combate ao racismo. Assim, como afirmamos em Sito $(2014$, p. 271), "parece que a dicotomia "cotas sim ou não" invisibilizou questionamentos, estudos e políticas necessárias para a dimensão do planejamento e da implementação da política", restringindo seu escopo ao ingresso. Com a entrada dos estudantes cotistas na universidade, as questões sobre a permanência passaram a emergir da experiência real dos próprios estudantes (SITO, 2016, p. 174, grifos nossos).

Em artigo recente, estudantes kaingang da Universidade de Ponta Grossa, Paraná, relatam suas estratégias de enfrentamento de toda sorte de dificuldades, especialmente as que envolvem situações de racismo por parte da sociedade nãoindígena. Para eles, a figura do indígena universitário, "que precisa conquistar o direito a estar ali diariamente, se firma a partir especialmente da organização dos próprios indígenas, que lutam tanto pelo acesso, quanto pela permanência no ensino superior, situações das quais a universidade só tem a se beneficiar, caso tenha 
sensibilidade de percebê-las dessa forma" (ANASTÁCIO; PEREIRA; FRAGA, 2017). Os alunos afirmam que re-existência é uma palavra-chave quando se tenta entender a permanência dos povos indígenas, bem como de suas línguas e culturas, apesar de todos os ataques que sofrem desde a invasão do Brasil pelos portugueses, em 1500 .

Aqui o genocídio indígena só não foi total porque, de alguma forma (à época e ainda hoje), conseguimos resistir às atrocidades de que fomos e somos vítimas, violência que nos forçou a um renascimento, a uma re-existência que, salvo raras exceções, não pode prescindir da convivência com os não-indígenas, o que não significa que esta se dê de forma pacífica, conjunta, partilhada. E no processo de re-existência é fundamental que reencontremos nossas vozes, as quais foram silenciadas. Porque somente com nossas vozes é que poderemos contar nossas histórias - do passado e do presente - a partir no nosso ponto de vista (ANASTÁCIO; PEREIRA; FRAGA, 2017, p. 3).

Ocupando as fronteiras, os espaços intermediários entre formas de pensar, escrever e produzir conhecimento, os letramentos acadêmicos indígenas e quilombolas em uma perspectiva de política afirmativa são marcados pela desterritorialização, pela coletividade, pelo protagonismo e pelo seu caráter político, características abordadas a seguir.

Desde o ensino básico, as especificidades das políticas educacionais para os estudantes indígenas preveem a garantia de identidades coletivas, situadas em relação direta com a existência de territórios e de sua manutenção (LIMA \& BARROSO-HOFFMANN, 2007; LÁZARO, 2015). O conceito de "territórios etnoeducacionais" foi apresentado em 2007 no Plano de Desenvolvimento da Educação (PDE) pelo então Ministro da Educação Fernando Haddad ${ }^{7}$. Posteriormente, em 2009, o Decreto Presidencial 6.861, que "dispõe sobre a Educação Escolar Indígena, define sua organização em territórios etnoeducacionais" fortaleceu o conceito de territorialidade na política de educação escolar indígena:

Cada território etnoeducacional compreenderá, independentemente da divisão políticoadministrativa do país, as terras indígenas, mesmo que descontínuas, ocupadas por povos indígenas que mantêm relações intersocietárias caracterizadas por raízes sociais e históricas, relações políticas e econômicas, filiações linguísticas, valores e práticas culturais compartilhados. ${ }^{8}$

$\mathrm{Na}$ universidade, porém, longe da aldeia e de suas práticas cotidianas, o estudante indígena está desterritorializado. Deleuze e Guattari afirmam sobre o caráter minoritário da língua desterritorializada:

7. MEC: Plano de Desenvolvimento da Educação: razões, princípios e programas. Brasília, 2007.

8. Decreto Presidencial 6.861/2009. 
O caráter minoritário de uma língua estende-se às condições de uma prática minoritária e revolucionária em toda língua. "Menor" é aquela prática que assume sua marginalidade em relação aos papéis representativos e ideológicos da língua e que aceita a desterritorialização (enquanto exílio) no interior das práticas comunicativas majoritárias, sendo estrangeiro na própria língua, envergonhando-se, gaguejando, deixando emergir o sotaque e o estranhamento de quem fala fora do lugar e ainda assim aceita e assume o não-lugar como seu deserto, na impossibilidade de uma origem (DELEUZE; GUATTARI, [1977] 2002, p. 28-29).

A formação do estudante indígena e do estudante quilombola é, destarte, assunto de interesse de toda sua coletividade, e a universidade deve prever mecanismos de participação efetiva das lideranças, anciãos, mulheres, mestres tradicionais e demais componentes sociais no acompanhamento da formação do estudante, fomentando e estimulando a correlação dos fenômenos de sua vida com os variados campos disciplinares da sua formação. As condições para esses estudantes enfrentarem as exigências da vida acadêmica até a diplomação passam, portanto, pelo desenvolvimento de ações de permanência que valorizem os saberes e a significativa experiência cultural com que eles chegam às instituições. $\mathrm{Na}$ Universidade Federal do Rio Grande, o kujã Kaingang Jorge Garcia participou com um ritual das defesas de mestrado e de doutorado do estudante Darci Emiliano, o primeiro pós-graduando de sua etnia na universidade. Tal prática tem se repetido em muitas universidades brasileiras onde as ações afirmativas propiciam o encontro dos saberes acadêmicos com os saberes tradicionais.

Pertencer a um coletivo respalda a luta não só pelas suas territorialidades, mas também por tudo o que elas contêm: o sangue dos antepassados, aspectos culturais como a comida e o artesanato, a arte, a música, a língua, a educação tradicional das crianças. Portanto, a re-existência não se dá em uma enunciação individualizada, separável da enunciação coletiva. A discursividade é assim uma discursividade de grupo, comprometida com a coletividade e a sua luta. Daí que a participação nos coletivos passa a ser uma participação política, nem sempre por razões ideológicas intencionais, mas porque "se encaixa" nas condições de enunciação coletiva de um povo, o que lhe confere características de "permanência". Assim, o aspecto imediatamente político do letramento acadêmico de indígenas e quilombolas não tem a ver com seu conteúdo ideológico, mas com sua performance enquanto uma multiplicidade de atos de fala que forma um todo expressivo e afirmativo:

Os quilombolas nunca terão sua cidadania plena enquanto a sua identidade for contestada e seus direitos não forem exercidos por eles mesmos. A identidade de resistência que une os quilombolas os manteve firmes lutando por seus direitos até hoje: empatia, igualdade de direitos e respeito é o que se busca, afinal somos iguais perante a lei. Mas a realidade é bem diferente do que está posto na lei. Enquanto houver discricionariedade e a vontade de alguns em detrimento de outros, não se pode falar em igualdade de direitos. Quando um grupo 
étnico é silenciado e subjugado, não the é dado o exercício de sua cidadania. (Rosane, estudante quilombola, formanda do curso de Direito)

Temos muitos sonhos, traçamos diferentes caminhos, contudo, independentemente de onde formos jamais esqueceremos as raízes e valores oriundos da nossa etnicidade, pois para nós, povos quilombolas, nossa cultura deve ser respeitada e valorizada, pois somos parte da formação bistórica do nosso país. (Mariele, estudante quilombola, formanda do curso de Pedagogia)

A importância da coletividade que antecede o indivíduo não diz respeito apenas à aldeia, mas também ao grupo de pares que se forma no seio da universidade. Em uma experiência nova (ações afirmativas), em um país de mudanças sociais rápidas, a flexibilidade com que os coletivos sociais e o movimento estudantil abalam a estrutura hegemônica da academia são o cenário possível de uma reterritorialização, de potências e devires para um agenciamento necessariamente político e marcadamente múltiplo ou coletivo. E neste espaço "entre", o meio do caminho que não é território de ninguém, é que eles se apropriam de novos sentidos e lhes atribuem o valor que desejam. A consciência crítica que desenvolvem ao longo de sua atuação nos coletivos revela-se em uma escrita questionadora, consciente do seu lugar de fala, que ora apresenta-se timidamente

Realizar este estudo é uma maneira de aproveitar a oportunidade que é dada ao povo indígena de estar na universidade produzindo conhecimento de uma cultura diferente. Falar sobre um clube de futebol da minha aldeia é tratar dos valores, das crenças, dos saberes daquela comunidade, chamando atenção do respeito à diversidade. Estar no mundo acadêmico é um feito de grande importância em particular, pois aprendemos a conviver com as dinâmicas do homem branco. De outra parte, este mundo tem que perceber que as culturas não são iguais. (Édson, estudante Guarani, último ano, curso de Educação Física)

\section{Ora com bastante veemência:}

Este projeto de pesquisa é um grito de guerra a favor da descolonização e homogeinização da escrita acadêmica levando em conta as relações de (des) pertencimento e (in) visibilidade que estão imbricadas nesse processo. Eu, NEGRA, sou diferente, logo preciso ser respeitada na forma de expressão que sei utilizar. (Sônia, estudante negra, mestranda em Educação Ambiental)

Ora, a universidade é ao mesmo tempo um lugar de reprodução de ideologias de dominação quanto um espaço propício à aquisição de consciência política e à luta por direitos e cidadania. Para o antropólogo José Jorge de Carvalho, responsável pelo projeto de Encontro de Saberes da UnB, ingressar nas universidades públicas federais não é apenas uma porta de entrada no mercado de trabalho, mas sim é o acesso ao topo da pirâmide deste mercado. A juventude negra, a juventude indígena, a juventude LGBT sabe porque luta para entrar na universidade: porque esta é a instituição formadora dos quadros de gerenciamento, de direção e de formulação 
da vida nacional em todos os seus domínios: na ciência, na cultura, na tecnologia, na economia, na política, na educação (CARVALHO, 2005).

Os primeiros trabalhos de conclusão de curso e dissertações de mestrado de estudantes indígenas e quilombolas que acessaram o sistema de cotas raciais são textos que nos mostram que certos conhecimentos não se veiculam em uma língua colonizadora. Ou que pensamentos complexos, holísticos, circulares, não compartimentados felizmente não podem ser totalmente colonizados. Isso tem um grande mérito, que a academia infelizmente não costuma valorizar.

A inexistência de referenciais oficiais para a educação superior indígena e quilombola, seja no que se refere à política linguística, seja no que diz respeito à sua implementação de forma geral, reflete a necessidade de que propostas para a formação superior dos povos tradicionais sejam elaboradas localmente, de acordo com a realidade sociocultural e os interesses específicos dos grupos envolvidos. $\mathrm{O}$ fato de delegar às instituições o compromisso de desenvolver tais projetos pode ser um risco no momento em que estas passam a ser as principais, senão as únicas responsáveis pela elaboração de propostas político-pedagógicas em prol das línguas e culturas minoritárias. Por essa razão é importante que haja protagonismo e representatividades dos intelectuais pretos, pardos, indígenas e quilombolas na elaboração dessas políticas, que passam por:

1. Fomentar a capacitação de profissionais universitários para intervir e transformar suas instituições no sentido da democratização do acesso e da permanência em seus cursos de indivíduos integrantes de povos tradicionais, fazendo-o em diálogo com suas coletividades;

2. Desenvolver atividades de leitura, escrita e discussão de textos acadêmicos para um letramento de re-existência respeitando os repertórios meta-cognitivos das línguas de partida dos estudantes e seus graus de proficiência em português;

3. Incluir as línguas indígenas em campos de atuação da vida acadêmica como por exemplo no currículo Lattes (no campo idiomas, não anonimamente como Outra língua), no ingresso pelo vestibular, nos resumos de trabalhos científicos, como segunda língua para os cursos de pós-graduação, etc.;

4. Inserir nas bibliografias das disciplinas textos pertinentes aos conhecimentos indígenas e quilombolas, bem como criar disciplinas de "Encontros de Saberes";

5. Abrir espaço para a produção científica intercultural de novos conhecimentos acerca das realidades contemporâneas, a partir de suas próprias perspectivas em 
cruzamento com as matrizes curriculares dos cursos dos estudantes indígenas e quilombolas;

6. Realizar atividades que permitam a promoção de relações sociais pautadas pelos princípios da interculturalidade crítica e do respeito à tolerância cultural e étnica, promovendo a valorização de todas as formas de conhecimentos e saberes existentes;

7. Promover empoderamento sociopolítico dos estudantes indígenas tanto para a sua formação acadêmica quanto para a sua atuação profissional crítica sobre as questões político-sociais que permeiam as necessidades dos seus povos.

\section{CONCLUSÃO}

O percurso desde uma identidade de resistência em relação a uma lógica da dominação até uma redefinição dos lugares de atuação discursiva dos universitários indígenas e quilombolas passa por assegurar que falantes de línguas e variedades minoritárias possam entender e ser entendidos em atos políticos, acadêmicos, jurídicos e administrativos nas instituições de ensino superior, minimizando a desvalorização e o estigma que sofrem dentro da comunidade acadêmica. Isso passa por programas de conscientização e de combate a preconceitos dos docentes, administradores e discentes nas instituições e por ações de visibilidade em torno dos direitos dessas populações.

Retomamos a pergunta da estudante que indaga: "Somos todos Arial 12 com espaçamento 1,5?" e que ficou ecoando por muito tempo durante o acompanhamento pedagógico de sua escrita. Construir uma resposta para esta questão passa por reelaborar muitas vezes essa pergunta, passa pela consciência dessa escrita entre outras, pela apropriação dessa escrita sem abrir mão de outras e até mesmo com a ruptura proposital dessa escrita. Um diálogo entre escritas. O que interrogamos agora é se é possível nessa linguagem expressar outras formas de conhecimento. Se nós questionamos esse poder em suas diversas formas, talvez faça parte disso buscar uma equidade entre pessoas que chegam à academia. Ter uma consciência crítica sobre isso é o primeiro passo para se afirmar suas identidades.

Para isso, há duas frentes de trabalho a empreender: na dimensão da aquisição de certos saberes, o acompanhamento da permanência dos estudantes na universidade depende também de que eles adquiram um certo letramento acadêmico, não só oral, mas também escrito. A universidade está preparada para uma pedagogia culturalmente sensível no acolhimento e no acompanhamento da leitura, da escrita e da discussão nos gêneros textuais acadêmicos que ela própria 
exige para a sua permanência? Em outra direção, a universidade também pode e deve ser o lugar onde se aprendem, se ensinam, se registram os saberes tradicionais, autóctones, e o conhecimento que eles veiculam. Que línguas indígenas, por exemplo, sejam consideradas com status de língua de conhecimento, de ciência, de intelectuais, de internacionalização, de revitalização para a cultura dos próprios indígenas e para a troca de saberes. Em outras palavras, a premissa de uma educação superior emancipatória, intercultural, crítica e decolonial deve promover melhorias significativas na vida de todos os sujeitos, permitindo-lhes novas formas de inserção na sociedade brasileira com ênfase em uma cidadania que respeite e integre as diferenças.

\section{$\overline{\text { REFERÊNCIAS }}$}

ANASTACIO, J.; PEREIRA, R.; FRAGA, L. (2018). Reexistência indígena na Universidade Estadual de Ponta Grossa: para além do acesso ao ensino superior. In: Souza, A. L.; Silva, I. J.; Muniz, K. Letramentos de reexistência - um conceito em movimentos negros. Revista da Associação Brasileira de Pesquisadores/as Negros/as (ABPN), [S.1.], v. 10, p. 01-11.

BARROSO-HOFMANN, M. (2005). Direitos culturais diferenciados, ações afirmativas e etnodesenvolvimento: algumas questões em torno do debate sobre ensino superior para os povos indígenas no Brasil. Anais do Simpósio Antropologia Aplicada y Políticas Públicas do $1^{\circ}$ Congreso Latinoamericano de Antropologia - ALA. Rosário, Argentina. De 11 a 15 de julho de 2005.

CARVALHO, J. J. (2005). Inclusão Étnica e Racial no Brasil. A Questão das Cotas no Ensino Superior. São Paulo: Attar Editorial.

DELEUZE, G.; GUATTARI, F. (1977). Kafka: por uma literatura menor. Tradução de Júlio Castañon Guimarães. Rio de Janeiro: Editora Imago, 2002.

DOEBBER, M. B. (2017). Indígenas Estudantes nas Graduações da UFR GS: movimentos de re-existência. Tese (Doutorado). Universidade Federal do Rio Grande do Sul, Faculdade de Educação, Porto Alegre, R.S.

ESCOBAR, A. (2003). Mundos y conocimientos de outro modo: el programa de investigación de modernidad/colonialidad latinoamericano. Tabula Rasa, n. 1, p. 51 86.

FETTERMAN, D. (1989). Ethnography: Step by Step. Newbury Park, CA: Sage. 
FLICK, Uwe. Desenho da pesquisa qualitativa. Porto Alegre, ARTMED, 2008.

FREITAS, A. E. C. (org.). (2015). Intelectuais indígenas e a construção da universidade pluriétnica no Brasil: povos indígenas e os novos contornos do programa de educação tutorial/conexões de saberes. 1. ed. - Rio de Janeiro: E-papers.

FREITAS, A. E. de C.; HARDER, E. (2013). Entre a equidade e a assimetria de poder: uma análise da implementação de políticas afirmativas de educação superior indígenas no Brasil. Século XXI: Revista de Ciências Sociais, Santa Maria: UFSM/PPGCS, v. 3, n. 1, p.62-87, jan./jun.

KLEIMAN, A. B. (org.). (1995). Os significados do letramento: uma nova perspectiva sobre a prática social da escrita. Campinas, Mercado das Letras.

LÁZARO, A. (2015). Notas de gestão: memórias e sentidos da criação de grupos de educação tutorial indígena no âmbito do Programa de Educação Tutorial/PET/MEC. In: FREITAS, Ana Elisa de Castro (org.). Intelectuais indígenas e a construção da universidade pluriétnica no Brasil: povos indígenas e os novos contornos do programa de educação tutorial/conexões de saberes. - Rio de Janeiro: E-papers.

LEA, M. R.; STREET, B. (1998). Student writing in higher education: an academic literacies approach. Studies in Higher Education 23(2): 157-172.

LILLIS, T. (1999). Whose "Common Sense"? Essayist literacy and the institutional practice of mystery. In: Jones, C.; Turner, J.; Street, B. (orgs.). Students writing in the university: cultural and epistemological issues. Amsterdam: John Benjamins Publishing.

LILLIS, T.; SCOTT, M. (2007). Defining academic literacies research: issues of epistemology, ideology and strategy. Journal of Applied Linguistics (JAL), Londres, vol. 4, n.1, pp. 05-32. Disponível em: http://dx.doi.org/doi:10.1558/japl.v4i1.5. Acesso em: 15.09.2018.

LIMA, A. C. de S.; BARROSO-HOFFMANN, M. (orgs.) (2007). Seminário desafios para uma educação superior para os povos indígenas no Brasil: políticas públicas de ação afirmativa e direitos culturais diferenciados. Rio de Janeiro: Museu Nacional/LACED.

MALDONADO-TORRES, N. (2008). La descolonización y el giro des-colonial. Tábula Rasa, v.2, n.9, p. 61-72.

MIGNOLO, W. (2003). Histórias locais/projetos globais: colonialidade, saberes subalternos e pensamento liminar. Tradução de Solange Ribeiro de Oliveira. Belo Horizonte, Ed. UFMG. 
MIGNOLO, W. (2008). Desobediência epistêmica: a opção descolonial e o significado de identidade em política. Cadernos de Letras da UFF, Dossiê: literatura, língua e identidade, n. 34, p. 287-324

MIGNOLO, W. (2015). Pensamiento decolonial, desprendimiento y apertura. In.: MIGNOLO, W. (org.), Habitar la frontera: sentir y pensar la decolonialidad. Barcelona: CIDOB.

NASCIMENTO, A. M. do. (2012). Português Intercultural: fundamentos para a educação linguística de professores e professoras indígenas em formação superior específica numa perspectiva intercultural. Tese (Doutorado em Letras). UFG, Faculdade de Letras.

SCOTT, M. (1999). Agency and subjectivity in student writing. In: Jones, C., Turner, J. and Street, B. (eds.) Students Writing in the University: cultural and epistemological issues. Amsterdam: John Benjamins.

SHOHAMY, E. (2006). Language policy: bidden agendas and new approaches. Londres/Nova Iorque: Routledge.

SOUZA, A. L. S. (2011). Letramento da reexistência. Poesia, grafite, música, dança: bip-bop. São Paulo: Parábola.

SITO, L. (2010). Ali tá a palaura deles: um estudo sobre práticas de letramento em uma comunidade quilombola do litoral do estado do Rio Grande do Sul. Dissertação de Mestrado. Universidade Estadual de Campinas, SP, 2010.

SITO, L. (2016). Escritas afirmativas: estratégias criativas para subverter a colonialidade em trajetórias de letramento acadêmico. Tese de Doutorado. Universidade Estadual de Campinas, SP, 2016.

STREET, B. V. (1995). Letramentos sociais: abordagens críticas do letramento no desenvolvimento, na etnografia e na educação. São Paulo: Parábola Editorial, 2014.

WALSH, C. (2007). Interculturalidad crítica y pedagogia decolonial. Memorias del Seminario Internacional Diversidad, Interculturalidad y Construcción de Ciudad. Bogotá: Universidad Pedagógica Nacional, 17-19 de abril de 2007.

WALSH, C. (2009). Interculturalidad, Estado, Sociedad. Luchas (de)coloniales de nuestra época. Quito: UASB/Abya Yala.

WALSH, C. (2013). Pedagogías decoloniales: prácticas insurgentes de resistir, (re)existir y (re)vivir. Tomo I. Quito, Ecuador: Ediciones Abya-Yala. 
ZAVALA, V. (2010). Quem está dizendo isso?: letramento acadêmico, identidade e poder no ensino superior. In: Vóvio, C. L.; Sito, L. S.; De Grande, P. B. Letramentos: rupturas, deslocamentos e repercussões de pesquisas em Linguística Aplicada. Campinas, SP: Mercado de Letras. pp. 71-95.

ZAVALA, V. (2011). La escritura académica y la agencia de los sujetos. Cuadernos Comillas 1, pp. 52-66.

Recebido: 23/10/2018

Aceito: 26/10/2018 